\title{
Calidad democrática en Argentina. Un análisis sobre cómo la rendición de cuentas horizontal impacta en la vida de las personas con discapacidad
}

\section{Democratic quality in Argentina. An analysis of how horizontal accountability impacts the lives of people with disabilities}

ARTÍCULO

\section{Sergio Hernán Blogna Tistuzza \\ Universidad Nacional de Quilmes, Argentina. Contacto: sergio_blogna@hotmail.com}

\section{Resumen}

Argentina tiene políticas públicas nacionales para el colectivo con discapacidad. En particular, analizamos el diseño e implementación de las políticas para garantizar la accesibilidad física en el transporte y la inclusión laboral en el ámbito público, a través del cupo laboral del $4 \%$ para trabajadoras y trabajadores con discapacidad. Sin embargo, la mera implementación de estas políticas no ha resultado suficiente para alcanzar las soluciones esperadas. Para lograr una transformación real se necesita el compromiso de los gobiernos, la disponibilidad de recursos que asigna el Parlamento $\mathrm{y}$, también, el funcionamiento de los organismos de control, que tienen a cargo la misión de asegurar que las políticas se implementen correctamente y los derechos se respeten. En otras palabras, desde la perspectiva de la rendición de cuentas horizontal de Guillermo O'Donnell, indagamos sobre la relación entre las dificultades de la implementación de las políticas públicas con la tarea de contralor de organismos del Poder Ejecutivo, el control parlamentario del Legislativo y el control del cumplimiento de las normas que dispone la Justicia.

Palabras claves: Democracia, discapacidad, derechos humanos, control interpoderes.

\section{Abstract}

Argentina has national public policies for the group with disabilities. In particular, we analyze the design and implementation of policies to guarantee physical accessibility in transportation and labor inclusion in the public sphere, through the $4 \%$ job quota for workers with disabilities. However, the mere implementation of these policies has not been sufficient to achieve the expected solutions. To achieve a real transformation requires the commitment of 
governments, the availability of resources assigned by Parliament and, also, the operation of control bodies, which are in charge of ensuring that policies are implemented correctly and rights are respected. In other words, from the perspective of the horizontal accountability of Guillermo O'Donnell, we inquire about the relationship between the difficulties of the implementation of public policies with the task of controlling executive branch agencies, the parliamentary control of the Legislature and the control of the fulfillment of the norms that the Justice has.

Keywords: Democracy, disabilities, human rights, accountability.

\section{Introducción}

El objetivo del presente artículo ${ }^{1}$ es indagar en la implementación de dos políticas públicas para las personas con discapacidad (la accesibilidad en el transporte ferroviario y la inclusión laboral) y el funcionamiento de los organismos de control para asegurar su correcto funcionamiento, entre los años 2010 y 2015. Las políticas públicas son la expresión o herramienta que el Estado utiliza para intervenir la realidad y dar respuesta a un problema público. Sin embargo, la mayor parte de las veces, con su mera implementación no es suficiente para alcanzar las soluciones esperadas. En concreto, si bien existen normas legales que ordenan la remoción de las barreras arquitectónicas en el transporte, estas barreras continúan existiendo. Para lograr una transformación real se necesita el compromiso de los gobiernos, la disponibilidad de recursos que asigna el Congreso y, también, el funcionamiento de los organismos de control, que tienen a cargo la misión de asegurar que las políticas se implementen correctamente y los derechos se respeten. En otras palabras, desde la perspectiva de la rendición de cuentas horizontal de Guillermo O'Donnell, indagamos sobre la relación entre las dificultades de la implementación de las políticas públicas con la tarea de contralor de organismos del Poder Ejecutivo, el control parlamentario del Legislativo y el control del cumplimiento de las normas que dispone la Justicia.

\footnotetext{
1 El presente artículo presenta una breve síntesis de mi tesis doctoral, titulada "Democracia y derechos humanos. Un análisis sobre cómo la rendición de cuentas horizontal impacta en la vida de las personas con discapacidad". La misma fue dirigida por Ana María Mustapic (Universidad Torcuato Di Tella) y Andrea Pérez (Universidad Nacional de Quilmes). Fue defendida y aprobada el 28 de julio de 2020, en la Universidad Nacional de Quilmes, con un jurado integrado por las doctoras Carina Scharagrodsky, Carolina Ferrante y Gabriela Ippolito-O’Donell. La versión completa de la tesis doctoral se puede consultar en el Repositorio Institucional Digital de Acceso Abierto de la Universidad Nacional de Quilmes, https://ridaa.unq.edu.ar/
} 
El período seleccionado para este trabajo trascurre entre los años 2010 y 2015. La razón de este corte temporal es que una de las dos políticas públicas a analizar, la destinada a la inclusión laboral de personas con discapacidad en el ámbito público, recién se reglamentó en 2010 al crear el cupo laboral del 4\%. Por esta razón, antes de esta fecha no hay registro de la cantidad de trabajadoras y trabajadores con discapacidad en el Estado nacional. Ello dificulta la evaluación de esta política pública antes de 2010 por la inexistencia de datos. Finalmente, decidimos concluir el análisis en el año 2015, cuando finalizó el último gobierno de Cristina Kirchner. Luego del cambio de gestión, se reorganizó el organigrama del Estado, se suprimieron organismos y se eliminaron políticas sociales, incluyendo varias destinadas a la población con discapacidad.

Es importante destacar que la investigación se realizó mediante un estudio cualitativo de naturaleza descriptiva, con una gran diversidad de fuentes: bibliografía especializada, diferentes normas legales de nivel doméstico, regional e internacional, informes de organismos internacionales y de organizaciones de la sociedad civil, expedientes de organismos públicos, publicaciones periodísticas, expedientes legislativos, expedientes judiciales y entrevistas a informantes claves. Nuestra hipótesis supone que la implementación de las políticas públicas relacionadas con la discapacidad responde a un desempeño deficitario de las instituciones de rendición de cuentas horizontal. Para ello, consideramos relevante poner el foco de atención en el comportamiento de estas instituciones de control tanto en el ámbito del Poder Ejecutivo como del Legislativo y el Judicial.

En virtud de la breve extensión de la publicación, decidimos organizar este trabajo en seis apartados. En el primero, mostraremos el nivel de cumplimiento de la normativa de accesibilidad física en el transporte ferroviario de pasajeros. En el segundo, indagaremos sobre el cumplimiento del cupo laboral del $4 \%$ para personas con discapacidad en el ámbito público. Por su parte, en el tercer apartado presentamos sintéticamente el marco conceptual sobre el accountability y su relación con la calidad democrática. En los siguientes tres apartados, presentamos un estudio descriptivo centrado en el funcionamiento de los tres poderes del Estado en su tarea de rendición de cuentas horizontal, relativo a la implementación y control de las políticas públicas de accesibilidad física e inclusión laboral.

\section{La accesibilidad física. Política pública para el transporte ferroviario de pasajeros y su efectividad}

Las barreras físicas impiden el desarrollo de la vida ciudadana de las personas con discapacidad, como poder trabajar, estudiar, vincularse socialmente, vivir en igualdad de condiciones que el resto. Por ello, la eliminación de estos obstáculos -físicos en este caso, debe ser una prioridad del Estado y del conjunto de la sociedad. Ello se traduce en el derecho a la accesibilidad, instituido en la Ley $\mathrm{N}^{\circ} 22.431$ y en la Convención sobre los 
Derechos de las Personas con Discapacidad. Esta norma estableció la supresión de las barreras arquitectónicas en el acceso y utilización de todos los medios de transporte público, con un plazo máximo que venció en el año 2000.

El análisis de una variedad de fuentes nos ha permitido concluir que esta política pública de accesibilidad no ha sido efectiva para cumplir con sus objetivos.

Cuadro 1. Elementos de accesibilidad en las estaciones de las líneas San Martín, Sarmiento, Mitre, Belgrano Sur, Roca y Urquiza, 2013.

\begin{tabular}{|l|l|l|l|l|l|l|}
\hline Línea & $\begin{array}{l}\text { Cantidad de } \\
\text { estaciones }\end{array}$ & Rampas & $\begin{array}{l}\text { Solados } \\
\text { Hápticos }\end{array}$ & Baños & Ascensores & $\begin{array}{l}\text { Apoyos } \\
\text { isquiáticos }\end{array}$ \\
\hline Urquiza & 23 & 10 & 1 & 2 & 9 & no informa \\
\hline Roca & 69 & 6 & 10 & 9 & 0 & 14 \\
\hline Belgrano Sur & 30 & 4 & 16 & 15 & 0 & 0 \\
\hline San Martín & 20 & 0 & 0 & 0 & 0 & 2 \\
\hline Mitre & 37 & 8 & 0 & 0 & 2 & 6 \\
\hline Sarmiento & 17 & 0 & 0 & 0 & 3 & 2 \\
\hline Belgrano Norte & 22 & 1 & 0 & 1 & 1 & 0 \\
\hline TOTAL & 218 & 29 & 27 & 27 & 15 & 24 \\
\hline
\end{tabular}

Fuente: elaboración propia en base a los expedientes CNRT 110509/2013 y Operadora Ferroviaria Sociedad del Estado (SOFSE) S02:0025646/2016.

Observaciones: la columna "solados hápticos" registra sólo aquellas con los tres tipos de solados, de guía, prevención y peligro, en todos los andenes. Asimismo, las columnas de "rampas", "baños", "ascensores" y "apoyos isquiáticos" registran a aquellas estaciones que cumplen esos requisitos en la totalidad de los andenes. En todos los casos se contabilizan sólo las "rampas" y "baños" en los que se ha verificado en informado el respeto a las pautas técnicas establecidas en la Ley 24.314 y su reglamentación.

Los expedientes de organismos públicos, reflejados en el cuadro 1, confirmaron que, para el período 2010-2015, ninguna de las siete líneas ferroviarias de pasajeros del Área Metropolitana de Buenos Aires había eliminado las barreras físicas. De un total de 218 estaciones, sólo 29 contaban con rampas, 27 tenían solados hápticos y baños accesibles, en 15 funcionaban ascensores y en 24 se constató la existencia de apoyos isquiáticos. La falta de concreción integral de estas obras revela una falta de cumplimiento de lo fijado por el marco normativo. Teniendo en cuenta que esta política pública requiere de recursos económicos para concretarse podría sostenerse que las limitaciones presupuestarias propias de un país en permanente crisis podrían explicar su inobservancia. Por esta razón, analizamos también el programa de inclusión laboral del colectivo con discapacidad. Esta política pública no requiere de inversiones ya que sólo prevé la inclusión laboral de 
trabajadoras y trabajadores con discapacidad para la cobertura de vacantes ya presupuestadas.

\section{Inclusión laboral de personas con discapacidad}

En Argentina, entre los años 2002 y 2003, el Instituto Nacional de Estadística y Censos de la República Argentina llevó a cabo la primera Encuesta Nacional de Discapacitados, conocida como ENDI. Este estudio informó una tasa de desocupación de la población con discapacidad del 15,8 \% y una tasa de ocupación del $24 \%$. Es decir, la mayor proporción del colectivo con discapacidad -alrededor de un $60 \%$ - no tenía trabajo ni lo buscaba (INDEC, 2005). Para avanzar con la inclusión laboral de este colectivo, la Ley $\mathrm{N}^{\circ}$ 22.431 dispuso un sistema cupo obligatorio, con sanciones, en el cual todo el Estado nacional tiene la obligación de emplear trabajadores y trabajadoras con discapacidad en una proporción no inferior al $4 \%$ del total de sus empleados.

Cuadro 2. Proporción de trabajadores con discapacidad sobre el total de la Administración Pública Nacional, del primer semestre 2010 al segundo semestre 2015.

\begin{tabular}{|c|c|c|c|c|c|c|c|c|c|c|c|c|}
\hline & 2010 & & 2011 & & 2012 & & 2013 & & 2014 & & 2015 & \\
\hline Semestre & $1 \mathrm{er}$ & 2do & $1 \mathrm{er}$ & 2do & $1 \mathrm{er}$ & 2 do & 1er & 2do & 1er & $2 d o$ & $1 \mathrm{er}$ & 2 do \\
\hline $\begin{array}{l}\text { Total de } \\
\text { trabajadores }\end{array}$ & 187.248 & 312.217 & 340.693 & 341.537 & 326.413 & 315.583 & 321.386 & 328.606 & 328.351 & 342.314 & 355.130 & 363.826 \\
\hline $\begin{array}{l}\text { Trabajadores } \\
\text { c/ disc. }\end{array}$ & 892 & 1.756 & 1.935 & 2.265 & 2.390 & 2.461 & 2.471 & 2.538 & 2.588 & 2.800 & 3.054 & 3.197 \\
\hline $\begin{array}{l}\text { Cupo laboral } \\
\text { (\%) }\end{array}$ & 0,48 & 0,56 & 0,57 & 0,66 & 0,73 & 0,78 & 0,77 & 0,77 & 0,79 & 0,82 & 0,86 & \\
\hline
\end{tabular}

Fuente: elaboración propia en base a los informes semestrales que elabora la Oficina Nacional de Empleo Público de la Subsecretaría de Gestión y Empleo Público, de la Secretaría de la Gestión Pública, de la Jefatura de Gabinete de Ministros.

Como revelan los informes oficiales de la Oficina de Empleo Público, sintetizados en el cuadro 2, durante el primer semestre 2010, esta proporción apenas alcanzaba un 0,48\%, y creció al $0,9 \%$ en el segundo semestre 2015 , a pesar de estar muy lejos de la meta legal establecida.

En los seis períodos semestrales analizados, el empleo creció en cinco de ellos y sólo en uno se respetó la reserva mínima del $4 \%$ de los nuevos cargos contratados. Estos datos explican el incumplimiento de esta política pública de cuotas, a pesar de que no requería de recursos económicos específicos. 


\section{Rendición de cuentas horizontal en Argentina}

La situación de vulneración de los derechos de las personas con discapacidad (por la falta de accesibilidad física en el transporte y el incumplimiento del cupo laboral) nos lleva a interrogarnos sobre la calidad de nuestra democracia, que parecería afrontar grandes dificultades para implementar las políticas públicas. Sobre este tema, Guillermo O’Donnell pone el énfasis sobre la democracia delegativa, que se caracteriza por la debilidad de los controles recíprocos en los espacios de la burocracia pública, o, en sus propias palabras, por el déficit de accountability horizontal (O’Donnell, 2001).

Al respecto, es necesario tener presente que, para este autor, existen dos tipos de accountability a la que están sometidos los gobernantes en las democracias contemporáneas: la vertical-electoral y la horizontal (O’Donnell, 2004). La accountability vertical refiere a las demandas que los ciudadanos realizan a los gobernantes y se ejerce por medio de "elecciones libres y limpias, en las que los ciudadanos pueden castigar o premiar a los gobernantes votando a favor o en contra de ellos en las próximas elecciones" (O'Donnell, 1998, p. 162). Las elecciones proporcionan a los ciudadanos dos modos discernibles para controlar a los gobernantes o para inducirlos a cumplir las propuestas programáticas y actuar en pos del bienestar general: 1) como mecanismos prospectivos las elecciones definen un mandato para el gobernante. Para quienes identifican el voto como un "mandato", las elecciones sirven para escoger buenas políticas o a políticos que traen buenas políticas; 2) como mecanismos retrospectivos o de rendición de cuentas. Para quienes identifican las elecciones como rendición de cuentas, consideran que éstas sirven para reclamarle al gobierno sus acciones del pasado, o exigirle el cumplimiento de promesas realizadas en campaña. En la medida en que el gobernante anticipa el juicio del electorado, o busca mantener buena imagen, se siente presionado a cuidar del buen desempeño en el ejercicio de su gobierno para contar así con el juicio favorable de los ciudadanos en las próximas elecciones ${ }^{2}$.

En cambio, el accountability horizontal, o rendición de cuentas horizontal, se refiere a la existencia de "agencias estatales que tienen autoridad legal y están tácticamente dispuestas y capacitadas para emprender acciones que van desde el control rutinario hasta sanciones legales o incluso impeachment, en relación con actos u omisiones de otros agentes o agencias del Estado que pueden, en principio o presuntamente ser calificadas como ilícitas" (O’Donnell, 2007, p. 99). Mientras los mecanismos verticales implican la existencia de controles externos sobre el Estado, el accountability horizontal se relaciona con la operación de un sistema interestatal de controles. Hace referencia a la existencia de ciertos organismos del Estado que cumplen la función de prevenir, indemnizar o sancionar

2 Cabe señalar, que Peruzzotti y Smulovitz (2006) introdujeron una tercera variante de accountability, la societal, para hacer referencia a las acciones que llevan a cabo los ciudadanos, al margen de las elecciones, para fiscalizar a las autoridades (Peruzzotti \& Smulovitz, 2006). 
acciones o inacciones presumiblemente ilegales de otros organismos. Se trata de un accountability que se orienta a garantizar que las acciones de los funcionarios públicos estén enmarcadas legal y constitucionalmente (Peruzzotti \& Smulovitz, 2006) y se guía por una lógica "republicana" de rectitud, por cuanto juzga a los actores políticos sobre la base del cumplimiento de leyes y normas, y del respeto de procedimientos considerados "correctos", pues se ajustan a procedimientos legales establecidos.

En las democracias latinoamericanas, el sistema de pesos y contrapesos es débil y la cultura política liberal y republicana está poco arraigada (O'Donnell, 1996). La tradición liberal no está consolidada debido a que la idea de que existen ciertos derechos que ningún tipo de poder puede invadir aún no es defendida por todas las fuerzas políticas y sociales. Precisamente, la tradición liberal se opone a la transgresión o invasión ilegal de un poder o autoridad pública - ejemplo de esto puede ser la cooptación del Congreso y del Poder Judicial por el Poder Ejecutivo-, porque representa una amenaza a los derechos y las libertades que gozan los ciudadanos. Tampoco se encuentra arraigada la tradición republicana, que se caracteriza por la defensa del imperio de la ley y por la convicción que los intereses públicos deben estar siempre por encima de los privados. La tradición republicana le asigna un valor superior a la esfera pública sobre la privada, considera que la gestión de la burocracia y la política pública deben estar orientadas a la identificación y defensa del bien público; se opone a la corrupción y considera que el desempeño de las funciones públicas es una actividad dignificante que exige cuidadosa sujeción a la ley y una entrega devota al servicio del bien público, por más que ello implique el sacrificio de los intereses privados (O'Donnell, 1996).

Asimismo, O'Donnell afirma que muchos de los regímenes existentes en América Latina no son democracias representativas, sino democracias delegativas. Con este concepto se refiere a aquellos países donde: "[...] se celebran elecciones libres y limpias, pero en los cuales los gobernantes especialmente presidentes se sienten autorizados a actuar sin restricciones institucionales" (O'Donnell, 1994). En esta concepción fuertemente mayoritaria y plesbicitaria del poder político el gobernante no deja de ser democrático, en el sentido que surge de elecciones libres y limpias y no intenta suprimirlas en el futuro. Pero no se siente obligado a aceptar las restricciones y los controles de otras instituciones constitucionales (Parlamento y Poder Judicial) ni de organismos estatales o sociales de control; al contrario, suele dedicarse a ignorar, anular o cooptar esas instancias. La idea básica de esta concepción es que los votantes ven al presidente como el depositario exclusivo de la legitimidad democrática al que en consecuencia delegan el derecho y la obligación de resolver los problemas del país a su leal saber y entender (O'Donnell, 2011).

Este modelo de democracia delegativa, en la que el presidente es el depositario exclusivo de la legitimidad democrática y en la que las instituciones y las restricciones constitucionales se devalúan y debilitan frente a dicha legitimidad mayoritaria del ejecutivo, 
ha estado alimentado y ha crecido debido a la influencia de la tradición democrática populista de los años cincuenta, y de la ola neoliberal de los años ochenta. Estas dos tradiciones políticas han incidido de modo tal que el constitucionalismo liberal en las democracias de América Latina -en particular, el relacionado con el sistema de frenos y contrapesos-, sea un instrumento débil a la hora de garantizar el principio de legalidad, representar los intereses de la ciudadanía y defender los derechos humanos de las intervenciones arbitrarias de las autoridades y poderes públicos (Peruzzotti \& Smulovitz, 2002).

En las democracias delegativas, el Estado tiene "múltiples caras" (O’Donnell, 2008). Marcelo Leiras explica que, en efecto, no actúa del mismo modo o con la misma intensidad para todos, (Leiras, 2012). Las caras representan distintos órdenes que se consagran, distintos servicios que se prestan y distintos vínculos que se producen en el nivel micro entre agentes estatales de toda índole y ciudadanos pertenecientes a distintos grupos sociales y territorios. "Para algunos grupos (los más ricos, por ejemplo), el Estado se muestra compasivo y protector, e incluso permeable a que estos grupos resuelvan sus necesidades por fuera de los instrumentos colectivos. Para otros grupos (los más pobres), el Estado se expresa de manera represiva, anulando identidades, discriminando y prestando servicios de mala calidad" (Bertranou, Estatalidad efectiva. Reflexiones sobre el estado a partir de los aportes de Guillermo O'Donnell, 2015).

En este marco conceptual, estudiamos cuál fue el rol de cada uno de los tres poderes del Estado nacional, durante 2010-2015, en relación a las dificultades de implementación de las políticas de accesibilidad física en el transporte y la inclusión laboral de personas con discapacidad.

\section{El control en el Poder Ejecutivo nacional}

Entendiendo que, si los organismos de rendición de cuentas horizontal que existen, cumplen su función de prevenir, indemnizar o sancionar acciones o inacciones de los otros, se logrará una mejor implementación de las políticas públicas, decidimos evaluar cuál ha sido el rol de los siete órganos y agencias del Poder Ejecutivo con responsabilidad en materia de la accesibilidad del transporte y la inclusión laboral. De los siete con competencia en la accesibilidad física y la inclusión laboral de personas con discapacidad, sólo uno posee atribuciones legales para prevenir, indemnizar o sancionar acciones o inacciones, requisito de la rendición de cuentas horizontal. Se trata en particular de la Comisión Nacional de Regulación del Transporte (CNRT), ente que podría haber aplicado sanciones por la falta de eliminación de las barreras en el transporte. Este organismo, para cumplir con su labor, requiere de "preparación técnica, independencia política y legitimación democrática. Y que esta legitimación democrática, precisamente, viene del sistema de designación, que debe serlo por concurso" (Gordillo, 2013). Sin embargo, desde principios del siglo hasta 2015, la CNRT se encontró intervenida, quedando a cargo de un interventor designado y removido 
por la cartera de transporte. En este caso encontramos que la autonomía del organismo se encontraba vulnerada, y con ello, su capacidad de acción (Skocpol, 1990) (Evans, 1996). El análisis de diversas fuentes nos confirma que -durante el período estudiado- la Comisión Nacional de Regulación del Transporte no cumplió con su misión de aplicación de las penalidades por la falta de accesibilidad física en el sistema ferroviario (Blogna Tistuzza, 2020). Ello nos permite entender por qué, pese a lo dispuesto en el marco legal, las personas con discapacidad no logran acceder al servicio de trenes en igualdad de condiciones que las demás personas. Un ejemplo de las múltiples caras del Estado de las que habla O'Donnell.

Del resto de los organismos, sólo el Instituto Nacional contra la Discriminación, la Xenofobia y el Racismo (INADI) ha demostrado determinación para iniciar y concluir investigaciones ante las denuncias de discriminación por parte del colectivo con discapacidad. Lamentablemente, si bien el INADI ha emitido dictámenes solicitando una reparación por la conducta discriminatoria, los mismos no son legalmente obligatorios y sólo constituyen recomendaciones.

En el caso de las siguientes cinco instituciones, el Consejo Federal de Discapacidad (CFD), la Sindicatura General de la Nación (SIGEN), el Comité de Asesoramiento y Contralor del cumplimiento de los artículos 20, 21 y 22 de la Ley $N^{\circ} 22.431$ (CAC), la Comisión Nacional Asesora para la Integración de las Personas con Discapacidad (CONADIS) y el Observatorio de la Discapacidad (OD), hemos detectado que no poseen atribuciones para la aplicación de sanciones por incumplimiento del marco legal sobre accesibilidad e inclusión laboral. En cambio, si tienen competencias para hacer seguimiento de las políticas públicas específicas sobre la temática en cuestión por lo que podrían haber llevado a cabo acciones para asegurar su correcta implementación. EI CFD no cumplió con su tarea de armonización legislativa ni propuso normas para asegurar que las políticas públicas mencionadas se implementen efectivamente. En el caso de la SIGEN, esta institución de auditoría podría haber denunciado formalmente en la Justicia a aquellos organismos que incumplen el cupo laboral. EI CAC, por su parte podría haber verificado el nivel de accesibilidad del transporte y elevado las denuncias de su incumplimiento ante la CONADIS pero tampoco lo hizo. Este último organismo no recibió denuncias por los temas aquí abordados, pero tampoco hizo relevamientos propios ni análisis sobre el cumplimiento del marco legal. De haberlo hecho, podría haber enviado las correspondientes denuncias a la SIGEN o la CNRT. Por último, el Observatorio de la Discapacidad -que había sido recientemente creado para hacer un seguimiento de la Convención sobre los Derechos de las Personas con Discapacidad- no tuvo asignado presupuesto ni empleados, y no demostró disposición de avanzar en su misión.

De esta manera, el trabajo de investigación develó el funcionamiento deficitario de las agencias de accountability horizontal en el Ejecutivo argentino. 


\section{El control parlamentario}

El control parlamentario, desde una perspectiva teórica jurídico-procedimental, es una subespecie concreta de los controles jurídicos integrado por dos momentos diferentes: el primero, cuando se determina si la actuación del sujeto corresponde al parámetro establecido, y el segundo, cuando el sujeto controlante impide al controlado la continuación de una actividad por no cumplir con los parámetros y eventualmente, le sanciona (García Morillo, 1985, pp. 41-42). Este modelo jurídico-procedimental, está vinculado con una perspectiva politológica del control parlamentario, conocida como control político, donde el sistema de pesos y contrapesos resultaría suficiente para entender la lógica de funcionamiento entra los poderes Ejecutivo y Legislativo. En esta noción, el control parlamentario sería un instrumento del esquema de rendición de cuentas el cual remite a la obligación de los gobernantes y la administración pública de informarse entre sí (rendición de cuentas horizontal). Sin embargo, el funcionamiento del sistema político argentino presenta una particularidad que comparte con otros países: los controles no son estrictamente institucionales -es decir, un Congreso que contrala al Ejecutivo-, sino de naturaleza política. En efecto, el Parlamento no opera respecto del control como un todo unificado ante su controlado, sino que su función de control -en tanto rama de gobierno- está determinada por el lugar que ocupan los legisladores en el proceso de gobierno: "si están en la coalición de gobierno intentarán disminuir y desactivar el control; si están en la oposición al gobierno procurarán activar el control" (Bieda, 2013, p. 8). Por ello, si la mayoría parlamentaria es oficialista, controlarán las comisiones legislativas y las convertirán en agentes del Poder Ejecutivo. En este escenario, sólo las y los parlamentarios de la oposición intentarán ejercer la función de control horizontal asignada constitucional y reglamentariamente a la institución donde se desempeñan (Bieda, 2013). En este sentido, el funcionamiento del sistema político argentino se asemeja más a la lógica partidaria típica de los parlamentarismos europeos, donde los alineamientos son por función de gobierno, entre gobierno y oposición (Mustapic \& Llanos, 2006).

Desde esta perspectiva, realizamos un análisis sobre el funcionamiento del Poder Legislativo con un estudio observacional, a través de dos variables independientes (permanencia y composición), en seis comisiones parlamentarias, con competencia en la accesibilidad física en el transporte y la inclusión laboral. Detectamos que cuatro de ellas registraron una alta señority (más antigüedad) en el período 2010-2015: las comisiones de Infraestructura, Vivienda y Transporte y de Trabajo y Previsión Social, del Honorable Senado, y las comisiones de Transportes y de Legislación del trabajo, de la Honorable Cámara de Diputados. Debemos tener presente que esta alta señority no son la regla general del Congreso sino, más bien, una excepción, ya que la baja tasa de reelección en el Congreso argentino es más baja que la media en el mundo. 
Respecto de la composición partidaria de las comisiones legislativas, nuestro análisis encontró que las comisiones consideradas "críticas" o importantes (las mismas que mostraron alta señority) fueron dominadas por el oficialismo, casi en su totalidad, y que las restantes dos comisiones (Población en la Cámara alta y Discapacidad en la Cámara baja) fueron cedidas a la oposición. Ello ha impactado negativamente en el control parlamentario, limitando la tarea de control de las y los legisladores. En el período 2010-2015, se registraron diecisiete pedidos de informes presentados en la Cámara de Diputados y catorce en el Senado, todos ellos impulsados por legisladoras y legisladores de la oposición. Sólo cuatro de los diecisiete fueron aprobados en Diputados, precisamente, durante el dominio de la oposición en la comisión de discapacidad. En el Senado, en cambio, ninguno de los catorce pedidos de informes presentados fue aprobado.

Como revelaron las fuentes parlamentarias, la falta de accesibilidad física y el cupo laboral para personas con discapacidad no fueron temas relevantes de la agenda legislativa. Y, en la práctica del control parlamentario, la alta señority y la dominación oficialista en las comisiones "críticas", convirtieron a las comisiones legislativas en agentes del Poder Ejecutivo. Sólo las y los legisladores de la oposición intentaron ejercer la función de control horizontal asignada, constitucional y reglamentariamente, al Congreso, pero el oficialismo lo impidió.

Respecto de las dos instituciones autónomas del Poder Legislativo, la Auditoría General de la Nación y la Defensoría del Pueblo de la Nación, realizamos un análisis sobre su actuación en el período y encontramos que habían llevado a cabo acciones para visibilizar las deficiencias en las políticas públicas de accesibilidad física y cupo laboral, pero que éstas no fueron consideradas ni valoradas por parte del Congreso Nacional.

\section{El control en el Poder Judicial}

Como expusimos anteriormente, las dos políticas públicas analizadas no lograron transformar la realidad de la forma que se había previsto normativamente. Las obras de accesibilidad en el transporte no se realizaron y el cupo laboral del $4 \%$ para trabajadoras y trabajadores con discapacidad no se cumplió. Luego, brevemente, encontramos serios problemas en los organismos de control dentro del Poder Ejecutivo. De los siete con competencia en las temáticas seleccionadas, sólo uno posee atribuciones legales para aplicar sanciones, requisito por definición de la rendición de cuentas horizontal. Sin embargo, este único organismo (Comisión Nacional de Regulación del Transporte) no ejerció plenamente su función y estableció la regulación necesaria para concretar penalidades ante la existencia de barreras arquitectónicas. Finalmente, en el estudio sobre el control parlamentario del Poder Legislativo, detectamos que la función de control está determinada por el lugar que ocupan los legisladores en el proceso de gobierno. Ello permite 
comprender por qué la mayoría del bloque oficialista en las comisiones importantes impidió que se activaran mecanismos de control sobre el gobierno, y sobre los incumplimientos de las políticas sobre discapacidad en particular. En este contexto, decidimos analizar cuál había sido el rol de la Justicia, concebida como el último eslabón en un Estado de Derecho para garantizar el cumplimiento de la legislación y el ejercicio efectivo de los derechos (Centro de Estudios Legales y Sociales; REDI; Asociacion Brindar Salud, 2004).

En primer lugar, es necesario tener presente que el Poder Judicial en Argentina ejerce el control de constitucionalidad ${ }^{3}$ a través de un sistema difuso, es decir, corresponde a todos los jueces, sin distinción de categorías, o jurisdicción nacional o provincial, ejercer esa función. En términos concretos, esto significa que cualquier ciudadano o ciudadana puede denunciar la inconstitucionalidad de una norma o la vulneración de un derecho ante cualquier tribunal de primera instancia (tribunal federal si la norma es nacional o tribunal provincial si la norma es sub-nacional). Todas estas sentencias son apelables ante una segunda instancia, conformada por distintas Cámaras Federales de Apelación según el fuero. Y, por último, en la cima de la jerarquía se encuentra la Corte Suprema de Justicia de la Nación, el máximo tribunal de justicia del país. Teniendo presente esta estructura institucional del mecanismo de Justicia, avancemos con los expedientes judiciales en detalle.

Luego de haber realizado un exhaustivo relevamiento de todas las causas judiciales sobre discapacidad para el período 2010-2015, ratificamos una de las conclusiones a las que llega Juan Antonio Seda en su tesis doctoral: la mayoría de las sentencias sobre discapacidad tratan sobre prestaciones de salud, generalmente contra obras sociales 0 contra empresas de medicina prepaga y, en menor medida, sobre educación (Seda, 2017, pág. 57). En consecuencia, en nuestro relevamiento detectamos que la judicialización del derecho a la inclusión laboral en el ámbito público de personas con discapacidad fue nula; no ha habido ningún reclamo en la Justicia durante 2010-2015. En cambio, sí registramos dos casos judiciales por la falta de accesibilidad en el transporte ferroviario, con movimientos en el período en estudio: a) Unión de Usuarios y Consumidores contra el Estado Nacional por la inaccesibilidad de la línea Sarmiento; b) Defensor del Pueblo de la Nación contra TBA, por las barreras arquitectónicas de las líneas Mitre y Sarmiento. Con el objetivo de analizar una mayor cantidad de casos que nos permitan obtener una mirada más profunda del funcionamiento de la Justicia, decidimos considerar -además- tres casos judiciales, que se cerraron antes de 2010, pero que se vinculan con los dos ya mencionados. En primer lugar, el caso María Inés Verbrugghe contra el Estado nacional y la empresa TBA, por la falta de accesibilidad en la línea Mitre, se inició en 1998 y concluyó en 2006, y es considerado un caso testigo para el resto de los expedientes. En segundo lugar y tercer lugar, los casos

${ }^{3} \mathrm{El}$ control de constitucionalidad es el mecanismo jurídico por el cual se revisan las normas ordinarias y, en caso, de contradecirse con la Constitución, se invalidan las de rango inferior. 
"Defensor del Pueblo de la Nación c/ UGOFE S.A. - Línea San Martín" y "Defensor del Pueblo de la Nación contra Ferrovías S.A.C. - Línea Belgrano Norte" son amparos judiciales que la Defensoría del Pueblo presentó en conjunto con el de las líneas Mitre y Sarmiento y, por lo tanto, nos parece pertinente indagar lo que ocurrió con cada uno de ellos. Debido a la síntesis que exige esta publicación, a continuación, mostramos en el cuadro 3 un resumen de los diferentes casos judiciales donde se exige que se cumpla con la normativa vigente y se eliminen las barreras arquitectónicas en el transporte.

Cuadro 3. Casos judiciales sobre accesibilidad en el transporte ferroviario de pasajeros.

\begin{tabular}{|c|c|c|c|c|c|}
\hline & Verbrugghe & $\begin{array}{l}\text { Unión de Usuarios } \\
\text { y Consumidores }\end{array}$ & DPN - UGOFE & $\begin{array}{l}\text { DPN - } \\
\text { Ferrovías }\end{array}$ & DPN - TBA \\
\hline Acción judicial & Amparo & Amparo & Amparo & Amparo & Amparo \\
\hline $\begin{array}{l}\text { Año de } \\
\text { presentación }\end{array}$ & 1998 & 2001 & 2005 & 2005 & 2005 \\
\hline Demandado & TBA y Estado & TBA y Estado & UGOFE S.A. & $\begin{array}{l}\text { Estado y } \\
\text { Ferrovías } \\
\text { S.A.C. }\end{array}$ & TBA y Estado \\
\hline Exigencias & \multicolumn{5}{|c|}{$\begin{array}{l}\text { Trato digno sin discriminación (obligaciones negativas) y la realización de obras pare } \\
\qquad \text { garantizar la accesibilidad física (obligaciones positivas) }\end{array}$} \\
\hline $\begin{array}{l}\text { Año de } \\
\text { finalización }\end{array}$ & 2006 & 2014 & 2007 & 2008 & 2016 \\
\hline $\begin{array}{l}\text { Decisión } \\
\text { judicial }\end{array}$ & \multicolumn{5}{|c|}{ Se ordena la realización de obras para garantizar la accesibilidad física } \\
\hline Plazos & 60 días & No se registran & 30 días & $\begin{array}{l}\text { No se } \\
\text { registran }\end{array}$ & $\begin{array}{l}\text { No se } \\
\text { registran }\end{array}$ \\
\hline Sanciones & Astreintes & No se registran & $\begin{array}{l}\text { No se } \\
\text { registran }\end{array}$ & Astreintes & $\begin{array}{l}\text { No se } \\
\text { registran }\end{array}$ \\
\hline Cumplimiento & Incumplida & Incumplida & Incumplida & Incumplida & Incumplida \\
\hline
\end{tabular}

Fuente: elaboración propia en base a expedientes judiciales.

El cuadro 3 nos permite ver que los cinco casos fueron iniciados a través de la herramienta constitucional denominada "recurso de amparo", diseñada como un instrumento 
sumarísimo, rápido y expedito. Sin embargo, todos ellos requirieron varios años para concluirse, uno de los recursos demoró dos años, por ejemplo, pero otros registran una demora de más de diez años. Según Maraniello, ello se debe a que el amparo "se ha ordinarizado, transformándose en una verdadera acción ordinaria de conocimiento" (Maraniello, 2011, p. 33), perdiendo entonces su efectividad como herramienta expedita.

Del análisis profundo de los cinco expedientes judiciales, podemos afirmar, en primer lugar, que la influencia jurídica de la Convención sobre los Derechos de las Personas con Discapacidad en la jurisprudencia no se reflejó en los casos estudiados; este tratado internacional no fue siquiera nombrado en los fallos dictados en posterioridad a su adopción por Argentina, en 2008. Ello confirma lo que Seda había detectado en los expedientes judiciales que analizó para su tesis doctoral (Seda, 2017, p. 179).

En segundo lugar, es importante remarcar que los cinco casos fueron presentados contra el Estado nacional y la empresa operadora, salvo el caso contra UGOFE - Línea San Martín, ya que la operadora no era privada sino estatal. En todos se reclamó por un trato digno y no discriminatorio con el colectivo con discapacidad y, en consecuencia, se exigieron las obras de adaptación necesarias como establece el marco legal. Independientemente del año en que se finalizó cada causa (es decir, cuando las sentencias quedaron firmes por el Máximo Tribunal), todas las decisiones judiciales fueron a favor de los demandantes y ordenaron que se garantice el derecho a la accesibilidad. Esto demuestra que el Poder Judicial se ocupó positivamente de la accesibilidad en el transporte ferroviario. En los cinco casos analizados, el Poder Judicial -a través de sus diferentes instituciones- cumplió con su función de balance, dando lugar a las denuncias recibidas y ordenando al Gobierno Nacional y las empresas el cumplimiento del marco legal vigente. A la vista de estos expedientes judiciales, encontramos que la Justicia argentina ejerció su rol en la rendición de cuentas horizontal, pero detectamos también que -a su vez- se enfrentó y se enfrenta ante una gran dificultad en el enforcement de estas decisiones judiciales. El enforcement hace referencia a la existencia de facultades legales de sanción y a la efectividad en la implementación de los castigos. Sin castigos efectivos, la rendición de cuentas que se desarrolla en las democracias es inocua y se debilita (Hernández Quiñones, 2011, p. 26).

Ninguno de los fallos judiciales -dictados en diferentes años y plazos- se cumplimentó. Ello cuestiona y erosiona la autonomía de la Justicia y su capacidad para hacer cumplir sus fallos. Recordemos que para que la democracia sea efectiva y los gobernantes actúen según el interés público, deben existir agencias institucionales autónomas y externas con la capacidad de imponer castigos efectivos y oportunos; y políticos y funcionarios dispuestos a acatar las eventuales sanciones negativas por sus actos ilegales e impropios.

La Corte Suprema de Justicia de la Nación se ocupó de marcar que el incumplimiento de una sentencia judicial constituye un desconocimiento de la división de poderes que resulta inadmisible en un estado de derecho y, en consecuencia, causa un grave deterioro 
del estado constitucional democrático. Poco sentido -sostuvo- cabría otorgarle a la garantía del debido proceso que consagra el artículo 18 de la Constitución Nacional si el Estado no asegura la prestación de un Servicio de Justicia que contenga mecanismos efectivos para hacer cumplir las decisiones que pongan fin a los conflictos con el Estado (Arte Radiotelevisivo Argentino S.A. c. Estado Nacional - JGM - SMC s/ amparo ley 16.986, 2014). Sin embargo, fue hace poco tiempo cuando el Máximo Tribunal tuvo que impedir que se suprimieran los efectos de las astreintes, advirtiendo que ello importaría privar a los jueces de uno de los instrumentos legalmente conferidos para ejercer su "imperium" (Peyrano, Pauletti, \& Esperanza, 2014).

Actualmente, si bien el Estado Nacional y sus agentes no pueden ser objeto de sanciones pecuniarias disuasivas, en cambio, sí de astreintes, pecuniarias y no pecuniarias, tendientes a que se cumplan mandatos judiciales desobedecidos. El principio de tutela judicial efectiva, que cuenta con rango constitucional así lo requiere y debe recordarse que entre las exigencias reclamadas por dicho principio se encuentra la de privilegiar la debida y pronta ejecución de las órdenes y resoluciones judiciales (Peyrano, 2013, p. 16). Y en este esquema, las astreintes son un recurso compulsivo para hacer cumplir sus resoluciones. Son sanciones pecuniarias, conminatorias y progresivas, que los jueces pueden imponer, con el fin de vencer la resistencia de las partes a cumplir con sus mandatos, es decir, que "su propósito es impeler u obligar a la parte deudora de la prestación a cumplir in natura con aquello que el juez ha mandado en una resolución, mediante el pago progresivo de una suma de dinero" (Highton \& Areán, 2004, p. 574).

En tal sentido, la finalidad de esta herramienta no es la de una indemnización de daños, ni una pena civil que sanciona el incumplimiento, sino que constituye un medio compulsorio para que el deudor procure aquello a que está obligado, en este caso, el depósito de las sumas embargadas a su dependiente (Antico, Graciela Mónica c/ Profumo, Jorge Osvaldo s/ Ejecución de acuerdo, 2018). El monto de las astreintes depende del arbitrio prudente del juez y no se mide por la importancia del daño que causa la demora del obligado en cumplir la manda judicial sino por la fuerza de resistencia del obligado. En este sentido las sanciones conminatorias nacen y se incorporan al patrimonio del requirente de ellas, desde la fecha de la decisión del juez que las decretó, pues su fundamento es el vencimiento del plazo establecido en la resolución y el apercibimiento de aplicarlas en caso de incumplimiento (Grillo, 2002).

$\mathrm{Su}$ uso se encuentra extendido tanto en las normas procesales como en los ordenamientos de fondo y se las puede hallar en el artículo 37 del Código Procesal (replicado por la mayoría de los códigos provinciales) y en el artículo 666bis del derogado Código Civil. Hasta la sanción del actual Código Civil y Comercial, existía consenso (aunque no unanimidad) respecto de la aplicabilidad de las astreintes a funcionarios públicos, con el objetivo de garantizar que la Administración Pública funcione bajo el imperio de la 
"Constitución y ley, y que dentro de otro orden de ideas, la coacción jurisdiccional judicial gravita por igual sobre las dos partes en el proceso, y sin distinción de que una de ellas sea el propio Estado [...]" (Canasi, 1973, p. 302). De hecho, existe jurisprudencia donde el Tribunal Superior de la Ciudad Autónoma de Buenos Aires (caso "Gorondon, Juan C. v. Ministerio de Desarrollo Social y otros", 06/02/2013) y la Corte Suprema de Justicia de la Nación (“Iturriaga, Ernesto A. c. Banco Central”, 27/02/1997) las convalidaron.

En la actualidad, el Código Civil y Comercial, al regular las sanciones conminatorias en su art. 804, limita su aplicación para incumplidores de resoluciones judiciales de carácter privado, al agregarle al texto del "Anteproyecto": "la observancia de los mandatos judiciales impartidos a las autoridades públicas se rige por las normas propias del derecho administrativo" (Degano, 2017). Esta derivación al derecho administrativo llevó el planteo a la Ley $\mathrm{N}^{\circ} 26.944$, de Responsabilidad del Estado, en donde solo se hace mención a los daños punitivos y no a las sanciones conminatorias. Por ello, aunque no existe una prohibición expresa de aplicar astreintes a las autoridades públicas en el artículo 804, algunos juristas han considerado que "pese a la defectuosa redacción, las autoridades públicas no pueden ser sancionadas mediante la imposición de astreintes" (Lorenzetti, 2015). Sin embargo, otros autores entienden que el Estado Nacional y sus agentes sí pueden ser objeto de sanciones pecuniarias conminatorias, (como las astreintes, pecuniarias y no pecuniarias), tendientes a que se cumplan mandatos judiciales desobedecidos, en base al principio de tutela judicial efectiva, que cuenta con rango constitucional (Peyrano, Pauletti, \& Esperanza, 2014). Incluso hay jueces que sostienen que renunciar a la aplicación de esta herramienta implicaría "una resignación deliberada de facultades propias del cargo que ejercen y que por otra parte son de la esencia del buen arte de juzgar en cuanto ello conlleva la potestad de hacer cumplir sus mandatos" (Marfil, 2016).

En conclusión, podemos afirmar que en los cinco casos analizados la Justicia ejerció positivamente su rol en la rendición de cuentas horizontal. Sin embargo, el incumplimiento de las sentencias dictadas a favor del colectivo con discapacidad evidenció una gran dificultad de los tribunales para ejercer el enforcement, producto de la inexistencia de instrumentos legales de sanción que obliguen a quienes deben llevar a cabo las acciones ordenadas a implementar las efectivamente. Debido a que el Estado nacional y sus agentes no pueden ser objeto de sanciones pecuniarias disuasivas, las astreintes son la única herramienta con las que cuentas las y los magistrados para coaccionar a que se cumplan los mandatos judiciales desobedecidos. Este instrumento -que fue limitado en el nuevo Código Civil y Comercial argentino- ha sido aplicado por dos tribunales inferiores en los casos Verbrugghe y Defensor del Pueblo de la Nación contra Ferrovías S.A.C. - Línea Belgrano Norte, pero tampoco funcionaron para asegurar el cumplimiento de los fallos, evidenciando las limitaciones del alcance de este tipo de sanciones para funcionarios de la 
Administración Pública. El incumplimiento de estas sentencias judiciales muestra con mayor claridad cómo el déficit en la rendición de cuentas horizontal se vincula con la falta de implementación de las políticas públicas para personas con discapacidad.

Como parte de las diferentes entrevistas que realizamos a actores claves, también consultamos sobre los motivos de esta situación. Desde la Defensoría del Pueblo de la Nación, la Dra. Pazos entiende que la falta de cumplimiento de las sentencias se explica porque las y los funcionarios no tienen incentivos para actuar de manera diferente, ya que saben que no serán sancionados. "Me animo a decir también que no hay una anomia boba (como dice el Prof. Nino) sino un incumplimiento deliberado y un recaer constante en actitudes discriminatorias de parte de funcionarios conscientes de su falta, pero no se recae judicialmente sobre el funcionario, ni aún en los casos que la ley así lo indica. Ahora, cuando la justicia embarga bienes propios del funcionario, la solución llega: recuerdo el caso de la falta de establecimientos para la recuperación de adicciones de jóvenes que tramitaba en el Juzgado del Juez Arias, en la ciudad de La Plata; cuando el Juez aplicó el embargo sobre el sueldo del funcionario, la solución no tardó en llegar" (Pazos, 2018). En cambio, desde Acceso Ya, la Dra. Macías pone el acento en el rol de la sociedad: "Creemos que se debe a la falta de conciencia social que lamentablemente existe y luchamos día a día por cambiarla, la accesibilidad la necesitamos todos en algún momento de la vida" (Macias, 2019).

\section{Reflexiones finales}

El minucioso trabajo de investigación llevado a cabo en la tesis doctoral y que, brevemente, resumimos en este trabajo, nos permite afirmar, que Argentina tiene un funcionamiento débil y limitado de los mecanismos de rendición de cuentas horizontal. Ello permite comprender la deficiente implementación de las políticas vinculadas con la discapacidad, para quienes el Estado tiene una "cara" distinta. Por ejemplo, la débil capacidad estatal de la Comisión Nacional de Regulación del Transporte, que podría explicarse por la falta de autonomía, refleja las dificultades para que el sistema ferroviario de pasajeros cumpla con la normativa de accesibilidad física. En virtud de que la capacidad estatal es la aptitud de los entes estatales para alcanzar los fines que le han sido asignados interna o externamente (Bertranou, 2015), en nuestro análisis detectamos importantes limitaciones en esa capacidad para hacer efectivos los derechos de las personas con discapacidad. Es importante que se desarrollen nuevos trabajos que, precisamente, pongan el foco en las capacidades reunidas por el Estado para satisfacer las demandas de este colectivo, por su incumbencia, en palabras de Charles Tilly, al proceso de democratización (Tilly, 2010). 


\section{Referencias bibliográficas}

Antico, Graciela Mónica c/ Profumo, Jorge Osvaldo s/ Ejecución de acuerdo, 47835/2016 (Cámara Nacional de Apelaciones en lo Civil Noviembre de 2018).

Arte Radiotelevisivo Argentino S.A. c. Estado Nacional - JGM - SMC s/ amparo ley 16.986 (Corte Suprema de Justicia de la Nación 11 de Febrero de 2014).

Bertranou, J. (2015). Capacidad estatal: Revisión del concepto y algunos ejes de análisis y debate. Revista Estado y Políticas Públicas(4), 37-59.

Bertranou, J. (enero-junio de 2015). Estatalidad efectiva. Reflexiones sobre el estado a partir de los aportes de Guillermo O'Donnell. Temas y debates(29), 33-51.

Bieda, T. (2013). El Control Parlamentario en la Argentina (tesis de maestría). Buenos Aires: Universidad Torcuato Di Tella. Recuperado de: https://repositorio.utdt.edu/bitstream/handle/utdt/2219/MCP_2013_Bieda.pdf?seque nce $=1 \&$ isAllowed $=y$

Blogna Tistuzza, S. H. (2018). El rol del Poder Nudicial en Argentina en cumplimiento de los derechos humanos de las personas con discapacidad. XIII Congreso Nacional y VI Congreso Internacional sobre Democracia (pp. 119-130). Rosario: Universidad Nacional de Rosario.

Blogna Tistuzza, S. H. (2018). La inclusión laboral de personas con discapacidad en el ámbito público de la provincia de Buenos Aires. III Simposio Internacional del Observatorio de la Discapacidad. Repensando categorías, abordajes, políticas, responsabilidades (pp. 273-287). Bernal: Universidad Nacional de Quilmes. Recuperado de: http://observatoriodiscapacidad.web.unq.edu.ar/wpcontent/uploads/sites/32/2018/09/Actas-III-Simposio-ODUNQ-2018-web.pdf

Blogna Tistuzza, S. H. (Octubre de 2019). La accesibilidad en el subterráneo de Buenos Aires. Los casos Aviani y Fernández. Revista Académica Discapacidad y Derechos(8). Recuperado de:

https://www.ijeditores.com/pop.php?option=articulo\&Hash=5c1fdc8a13b4878a7dc8 $14126806 \mathrm{e} 5 \mathrm{f} 1$

Blogna Tistuzza, S. H. (2020). Democracia y derechos humanos. Un análisis sobre cómo la rendición de cuentas horizontal impacta en la vida de las personas con discapacidad (tesis doctoral). Bernal: Universidad Nacional de Quilmes.

Canasi, J. (1973). Sanciones Conminatorias contra el Estado. Buenos Aires: La Ley.

Centro de Estudios Legales y Sociales; REDI; Asociacion Brindar Salud. (2004). Informe Alternativo presentado por el CELS ante el Comité para la Eliminación de Todas las Formas de Discriminación Racial. Buenos Aires: CELS. Recuperado de: http://www.cels.org.ar/common/documentos/cerd_personas_discapacidad.pdf

Comité sobre los Derechos de las Personas con Discapacidad (2012). Examen de los informes presentados por los Estados partes en virtud del artículo 35 de la Convención. Observaciones finales del Comité sobre los Derechos de las Personas con Discapacidad. Ginebra: Comité sobre los Derechos de las Personas con Discapacidad. Recuperado de: https://www.agro.uba.ar/sites/default/files/discapacidad/crpd-c-arg-co-1_sp.pdf

Degano, G. A. (13 de Noviembre de 2017). Las astreintes contra autoridades públicas y el artículo 804 del Código Civil y Comercial. Diario Civil y Obligaciones. 
Evans, P. (enero-marzo de 1996). El Estado como problema y como solución. Desarrollo Económico, 35(140).

Ferrante, C. (2007). Algunas reflexiones sobre la situación de discapacidad en la Argentina en la actualidad. IV Jornadas de Jóvenes Investigadores. Buenos Aires: Instituto de Investigaciones Gino Germani. Recuperado de https://www.aacademica.org/000024/173

Fraga, I. (1961). El parlamento británico. Madrid: Instituto de Estudios Políticos.

García Morillo, J. (1985). El control parlamentario del gobierno en el ordenamiento español. Publicaciones del Congreso de los Diputados.

Gordillo, A. (2013). Tratado de derecho administrativo y obras selectas. Buenos Aires: Fundación de Derecho Administrativo.

Grillo, I. I. (Julio de 2002). Las astreintes: el respeto a la justicia. Recuperado de: http://www.saij.gob.ar/doctrina/dacf020017-grillolas_astreintes_respeto_justicia.htm

Hernández de Gante, A. (Julio-Diciembre de 2018). Las zonas marrones en el pensamiento de O'Donnell. Reflexiones sobre el caso mexicano. Revista IUS, 12(42). Recuperado de: http://www.scielo.org.mx/scielo.php?script=sci_arttext\&pid=S1870$21472018000200109 \&$ Ing=es\&nrm=iso\&tlng=es

Hernández Quiñones, A. y. (2011). Aproximación conceptual. el accountability desde una perspectiva comparada en América Latina: estudios de caso. En A. y. Hernández Quiñones. Experiencias de accountability horizontal y social en América Latina. Estudios de caso comparados en São Paulo, México DF, Caracas y Bogotá. Bogotá: Ediciones Uniandes.

Highton, E., \& Areán, B. (2004). Código Procesal Civil y Comercial de la Nación (Vol. 4). Buenos Aires: Hammurabi.

Hwang, W., Jones, M. P., \& Micozzi, J. P. (2009). Government and Opposition in the Argentine Congress, 1989-2007: Understanding Inter-Party Dynamics through Roll Call Vote Analysis. Journal of Politics in Latin America, 1(1).

INDEC. (2005). La población con discapacidad en la Argentina, Encuesta Nacional de Personas con Discapacidad. Buenos Aires: INDEC.

Leiras, M. (2012). Homenaje a Guillermo O'Donnell. Congreso del CLAD. Cartagena.

Lorenzetti, R. L. (2015). Código Civil y Comercial de la Nación Comentado. Santa Fe: Rubinzal Culzoni.

Macias, M. J. (3 de Abril de 2019). Entrevista realizada por S. H. Blogna Tistuzza.

Mann, M. (Julio-Septiembre de 2004). La crisis del estado-nación en américa latina. Desarrollo Económico, 44(174), 179-198.

Maraniello, A. (Enero-Junio de 2011). El amparo en Argentina. Evolución, rasgos y características especiales. IUS, 5(27). Recuperado de: http://patriciomaraniello.com.ar/home/wp-content/uploads/2015/01/El-amparo-enla-Argentina-MARANIELLO-CORRECCIONES-ACEPTADAS.pdf

Marfil, A. M. (17 de Agosto de 2016). Astreintes y la inaplicabilidad del artículo 804, última parte, del Código Civil y Comercial. Diario Judicial. 
Mustapic, A. M., \& Llanos, M. (2006). Estudio introductorio. En A. M. Mustapic, \& M. Llanos. El Control Parlamentario en Alemania, Argentina y Brasil. Buenos Aires: Politeia.

O’Donnell, G. (Noviembre-Diciembre de 1993). Estado, Democratización y ciudadanía. Nueva Sociedad(128), 62-87.

O’Donnell, G. (2001). Accountability horizontal: la institucionalización legal de la desconfianza política. Revista Postdata(7), 11-34.

O’Donnell, G. (2008). Apuntes para una teoría del Estado. En G. O’Donnell. Catacumbas. Buenos Aires: Prometeo Editores.

O'Donnell, G. (enero-abril de 1989). Transiciones, continuidades y paradojas. Cuadernos Políticos(56), 19-36.

O’Donnell, G. (1996). Otra institucionalización La democratización y sus límites después de la Tercera Ola. Revista La Política.

O’Donnell, G. (1997). Rendición de cuentas horizontal y nuevas poliarquías. Nueva Sociedad (152).

O’Donnell, G. (1998). Accountability Horizontal. Revista la Política. Política y derecho. ¿Se oponen la democracia y el constitucionalismo?(4).

O'Donnell, G. (2004). Contrapuntos, ensayos escogidos sobre el autoritarismo y democratización. Buenos Aires: Paidós.

O’Donnell, G. (2007). Disonancias. Críticas a la democracia. Buenos Aires: Paidós.

O'Donnell, G. (2010). Democracia, agencia y estado: teoría con intención comparativa. Buenos Aires: Prometeo.

O'Donnell, G. (1994). Horizontal accountability and new polyarchies. Notre Dame: The Helen Kellogg Institute for International Studies.

O'Donnell, G. (2011). Nuevas reflexiones acerca de la democracia delegativa. En G. O'Donnell, O. lazzetta, \& H. Quiroga. Democracia Delegativa (pp. 19-33). Buenos Aires: Prometeo.

Oszlak, O. (2015). Políticas públicas y regímenes políticos: Reflexiones a partir de algunas experiencias latinoamericanas. En Capacidades estatales. Diez textos fundamentales (pp. 155-216). Buenos Aires: CAF.

Oszlak, O., \& O’Donnell, G. (1995). Estado y políticas estatales en América Latina: hacia una estrategia de investigación. Redes, 2(4), 99-128.

Pazos, C. (23 de Noviembre de 2018). Entrevista realizada por S. H. Blogna Tistuzza.

Peruzzotti, E., \& Smulovitz, C. (2002). Controlando la política: Ciudadanos y Medios en las nuevas democracias. Buenos Aires: Temas.

Peruzzotti, E., \& Smulovitz, C. (2006). Enforcing the Rule of Law. Social Accountability in the New Latin American Democracies. University of Pittsburgh Press.

Peyrano, J. W. (2013). Importancia de la consolidación del concepto de la tutela judicial efectiva en el ámbito del juicio civil y análisis de su contenido. En Herramientas procesales. Buenos Aires: Editorial Nova Tesis. 
Peyrano, J. W., Pauletti, A. C., \& Esperanza, S. (2014). ¿Pueden quedar impunes las desobediencias a mandatos judiciales cometidas por el Estado Nacional y sus agentes? El Derecho : diario de doctrina y jurisprudencia.

Peyrano, J., Pauletti, A., \& Esperanza, S. (2014). ¿Pueden quedar impunes las desobediencias a mandatos judiciales cometidas por el Estado Nacional o sus agentes? El Derecho: diario de doctrina y jurisprudencia. Recuperado de http://www.juscorrientes.gov.ar/wp-content/uploads/jurisprudencia/publicacionesjuridicas/pdf/2015/PUEDEN-QUEDAR-IMPUNES-LAS-DESOBEDIENCIAS-AMANDATOS-JUDICIALES.pdf?iframe=true $\&$ width $=95 \%$ \&height $=95 \%$

Ramírez León, L. (2011). Control parlamentario, mecanismo del Legislativo para co-dirigir al gobierno junto con el Ejecutivo. En R. López Flores, F. E. Rivas Prats, A. Hernández Cruz, \& A. Sainez Araiza. Estrategia y práctica parlamentaria en un Congreso plural. México .

Seda, J. A. (2017). Discapacidad y derecho. Impacto de la convención sobre los derechos de las personas con discapacidad. Buenos Aires: Jusbaires.

Shedler, A. (1999). Conceptualizing Accountability. The Self-Restraining State: Power and Accountability in New Democracies. Colorado: Lynne Rienner Publishers.

Skocpol, T. (1990). El Estado regresa al primer plano: estrategias de análisis en la investigación actual. En E. Torres Rivas. Política. San José de Costa Rica: Educa.

Tilly, C. (2010). Democracia. Madrid: Akal. 